\title{
Holi colours contain PM10 and can induce pro-inflammatory responses
}

\author{
Katrin Bossmann ${ }^{*}$, Sabine Bach ${ }^{1}$, Conny Höflich¹, Kerttu Valtanen², Rita Heinze ${ }^{3}$, Anett Neumann , \\ Wolfgang Straff ${ }^{1}$ and Katrin Süring ${ }^{1}$
}

\begin{abstract}
Background: At Holi festivals, originally celebrated in India but more recently all over the world, people throw coloured powder (Holi powder, Holi colour, Gulal powder) at each other. Adverse health effects, i.e. skin and ocular irritations as well as respiratory problems may be the consequences. The aim of this study was to uncover some of the underlying mechanisms.

Methods: We analysed four different Holi colours regarding particle size using an Electric field cell counting system. In addition, we incubated native human cells with different Holi colours and determined their potential to induce a pro-inflammatory response by quantifying the resulting cytokine production by means of ELISA (Enzyme Linked Immunosorbent Assay) and the resulting leukocyte oxidative burst by flow cytometric analysis. Moreover, we performed the XTT (2,3-Bis-(2-methoxy-4-nitro-5-sulfophenyl)-2H-tetrazolium-5-carboxanilide) and Propidium iodide cytotoxicity tests and we measured the endotoxin content of the Holi colour samples by means of the Limulus Amebocyte Lysate test (LAL test).

Results: We show here that all tested Holi colours consist to more than $40 \%$ of particles with an aerodynamic diameter smaller than $10 \mu \mathrm{m}$, so called PM10 particles (PM, particulate matter). Two of the analysed Holi powders contained even more than $75 \%$ of PM10 particles.

Furthermore we demonstrate in cell culture experiments that Holi colours can induce the production of the proinflammatory cytokines TNF-a (Tumor necrosis factor-a), IL-6 (Interleukine-6) and IL-1 $\beta$ (Interleukine-1 $\beta$ ). Three out of the four analysed colours induced a significantly higher cytokine response in human PBMCs (Peripheral Blood Mononuclear (ells) and whole blood than corn starch, which is often used as carrier substance for Holi colours. Moreover we show that corn starch and two Holi colours contain endotoxin and that certain Holi colours display concentration dependent cytotoxic effects in higher concentration. Furthermore we reveal that in principle Holi colours and corn starch are able to generate an oxidative burst in human granulocytes and monocytes. In Holi colour 1 we detected a fungal contamination.
\end{abstract}

Conclusions: Some of the observed unwanted health effects of Holi colours might be explained by the high content of PM10 particles in conjunction with the possible induction of a pro-inflammatory response and an oxidative leukocyte burst.

Keywords: Holi colours, PM10, Pro-inflammatory response, TNF-a, IL-6, IL-1 $\beta$, Oxidative burst

Abbreviations: BSA, Bovine Serum Albumin; E.coli, Escherichia coli; ELISA, Enzyme Linked Immunosorbent Assay; EU, Endotoxin Units; FCS, Fetal Calf Serum; IL-1ß, Interleukine-1ß; IL-6, Interleukine-6; IL-8, Interleukine-8; LAL, Limulus Amebocyte Lysate; LPS, Lipopolysaccharide; PBMCs, Peripheral Blood Mononuclear Cells; PBS, Phosphate buffered saline; PM, Particulate matter; SD, Standard deviation; TNF-a, Tumor necrosis factor a; VLE, Very low endotoxin; XTT, (2,3-Bis-(2-methoxy-4-nitro-5-sulfophenyl)-2H-tetrazolium-5-carboxanilide)

\footnotetext{
*Correspondence: katrin.bossmann@uba.de

${ }^{1}$ Environmental Medicine and Health Effects Assessment, Federal

Environment Agency, Corrensplatz 1, 14195 Berlin, Germany

Full list of author information is available at the end of the article
}

(c) 2016 The Author(s). Open Access This article is distributed under the terms of the Creative Commons Attribution 4.0 International License (http://creativecommons.org/licenses/by/4.0/), which permits unrestricted use, distribution, and reproduction in any medium, provided you give appropriate credit to the original author(s) and the source, provide a link to the Creative Commons license, and indicate if changes were made. The Creative Commons Public Domain Dedication waiver (http://creativecommons.org/publicdomain/zero/1.0/) applies to the data made available in this article, unless otherwise stated. 


\section{Background}

Holi is a traditional Hindu festival originated in India. Lasting for several days in spring and celebrating the victory of good over evil it is a very colourful event. Differences in people's caste, age, sex and status seem to be abrogated by throwing Gulal, a special coloured powder, at each other to make everybody and everything look equal. About 3 years ago, the traditional Indian festival was transferred to Europe and adapted to a commercial party event. Meanwhile it takes place in many different cities all over the world: people listen to music, dance and throw coloured powder. This so called Holi powder/Holi colour/Gulal powder or Micro Confetti is distributed by different companies. The quality and the amount of information given on the outer packaging about the ingredients of the particular Holi colour are mostly very poor. So far, there is no European or US regulation about Holi colours and it is not clear whether they should be categorised for instance as cosmetic products or general consumer products. Although many manufacturers claim that their products are harmless to health and environment, organisers of Holi festivals often recommend wearing eye and respiratory protection (like goggles and face masks) and advise people with respiratory disorders not to participate. There are several reports of adverse health effects probably caused by the use of Holi powder: various forms of cutaneous diseases [1] as well as ocular irritations [1, 2] and a case of periorbital necrotizing fasciitis [3] have been described after exposure to Holi colours. In addition, high total suspended particulate concentrations occurred during Holi events [4] that may also cause or aggravate adverse health effects like respiratory irritations.
To assess possible hazards to human health, we ordered four different Holi powder products of three different distributors via the internet and analysed them regarding particle size and their potential to induce proinflammatory responses in cell culture systems. Cellbased in vitro assays have been used widely to imitate in vivo situations [5, 6]. For example the whole blood assay was used to describe pro-inflammatory activity of dust sample extracts [7]. Moreover, we tested the cytotoxic potential of corn starch and the different Holi colours, analysed the endotoxin and mould content of corn starch and the Holi colours and screened for corn starch-/Holi colour-leukocyte interactions in vitro.

\section{Methods}

\section{Holi colours}

Four different Holi colour products were ordered via a renowned internet retailer. General information like producing country, ingredients or indications relevant for impacts on health either given on the internet or on the outer packaging of the product are shown in Table 1. As corn starch is often used as carrier substance for Holi colours, commercially available corn starch (RUF Lebensmittelwerk KG, Quakenbrück, Germany) designated as food ingredient was purchased to serve as a control.

\section{Electric field cell counting system (CASY $\left.{ }^{\circledR}\right)$ of corn starch and Holi particles}

We used a $\mathrm{CASY}^{\circledR}$ cell counter (Schärfe System $\mathrm{GmbH}$, CASY Cell Counter + Analyser System, Model TTC) with a $60 \mu \mathrm{m}$ measuring capillary to determine particle size and number of (i) BD Cytometer Setup and Tracking beads of 2 and $3 \mu \mathrm{m}$ diameter (Becton Dickinson,

Table 1 Available information on the different Holi colours, either communicated with the product itself or online

\begin{tabular}{|c|c|c|c|c|}
\hline $\begin{array}{l}\text { Holi Colour } \\
\text { Number }\end{array}$ & 1 & 2 & 3 & 4 \\
\hline $\begin{array}{l}\text { Shade/ } \\
\text { characterisation } \\
\text { of colour }\end{array}$ & $\begin{array}{l}\text { black/ Holi colour, } \\
\text { perfumed natural } \\
\text { colour, Holi powder } \\
\text { Gulal }\end{array}$ & $\begin{array}{l}\text { pink/ Holi powder (Holi gulal Holi colour), } \\
\text { used at Holi Festivals }\end{array}$ & $\begin{array}{l}\text { orange/ "Effect colour } \\
\text { powder", optically like } \\
\text { Holi powder/ Holi colours }\end{array}$ & $\begin{array}{l}\text { green/ Holi colour, } \\
\text { Gulal festival }\end{array}$ \\
\hline Produced in & India & Germany & n.s. & n.s. \\
\hline MSDS available & n.s. & yes & n.s. & n.s. \\
\hline EU Regulation & n.s. & $\begin{array}{l}\text { according to Art. } 19 \text { EU regulation of } \\
\text { cosmetic products }\end{array}$ & n.s. & n.s. \\
\hline Ingredients & $\begin{array}{l}\text { natural colour, } \\
\text { plant based }\end{array}$ & $\begin{array}{l}\text { corn starch, water, hydrated silica, sodium chloride, } \\
\text { sodium sulphate, E127 }\end{array}$ & n.s. & flour powder, dyed \\
\hline $\begin{array}{l}\text { Recommended } \\
\text { application }\end{array}$ & $\begin{array}{l}\text { Holi open air festivals, } \\
\text { creative areas }\end{array}$ & $\begin{array}{l}\text { Holi festivals, for throwing up into the air, sprinkle } \\
\text { powder onto hands and throw up into air } \\
\text { (away from body) for adult use only }\end{array}$ & $\begin{array}{l}\text { for decor use or throwing } \\
\text { up into the air }\end{array}$ & $\begin{array}{l}\text { for decor use or } \\
\text { throwing up into the air }\end{array}$ \\
\hline Warning & $\begin{array}{l}\text { environmental friendly, } \\
\text { mild on skin, nontoxic }\end{array}$ & $\begin{array}{l}\text { don't use with a history of asthma and allergies, } \\
\text { avoid contact with mucus membranes, wear } \\
\text { mouth, nose and eye protection, not edible }\end{array}$ & $\begin{array}{l}\text { don't use at festivals or } \\
\text { on skin, not classified as } \\
\text { cosmetic product }\end{array}$ & $\begin{array}{l}\text { don't use at festivals or } \\
\text { on skin, not classified as } \\
\text { cosmetic product }\end{array}$ \\
\hline
\end{tabular}


Lot: 22680), (ii) blank calibration particles (BD Biosciences, Lot: 63100) of 6.0-6.4 $\mu \mathrm{m}$ diameter, (iii) corn starch and (iiii) four different Holi colours. Respective particles were suspended in PBS (Phosphate buffered saline) (Biochrom, Berlin, Germany) and diluted with $\mathrm{CASY}^{\oplus}$ ton (La Roche Diagnostics GmbH, Basel, Switzerland) according to the manufacturer's instructions for measuring. Particle count was evaluated in a size range between 0.7 and $30 \mu \mathrm{m}$.

\section{Stimulation of PBMCs}

Blood was withdrawn under authorised supervision from six healthy donors who had given their informed consent. PBMCs were isolated from lithium heparin anti-coagulated blood by Ficoll-Paque ${ }^{\text {TM }}$ Plus (GE Healthcare Bio-Sciences $\mathrm{AB}$, Uppsala, Sweden) density gradient centrifugation and resuspended in VLE RPMI 1640 (Very Low Endotoxin) media (Biochrom AG, Berlin, Germany) supplemented with $10 \%$ (v/v) FCS (Fetal Calf Serum), 2 mM L-glutamine (Sigma Aldrich, Chemie GmbH, München, Germany) and $1 \%$ (v/v) penicillin/streptomycin (Biochrom AG, Berlin, Germany). $500 \mu \mathrm{l}$ of a suspension of PBMCs $\left(2 \times 10^{6}\right.$ cells/ $\mathrm{ml}$ ) were incubated in sterile 24-well plates (Multiwell ${ }^{\mathrm{TM}}$, Falcon ${ }^{\oplus}$, Becton Dickinson Labware, NJ, USA) for $4 \mathrm{~h}$ at $37{ }^{\circ} \mathrm{C}$ and $5 \% \mathrm{CO}_{2}$ with corn starch and the four different Holi colours (see above), respectively, each at $1.5 \times 10^{6}$ particles $/ \mathrm{ml}$. The utilised concentration of the Holi colours and corn starch arose from dose-effect experiments that we performed with ambient dust (data not shown). Cells treated with PBS only $(7.5 \% \mathrm{v} / \mathrm{v})$ served as negative control. Cells treated with LPS (Lipopolysaccharide) (Enzo Life Sciences, NY, USA) at $100 \mathrm{ng} / \mathrm{ml}$ served as positive control. Samples were centrifuged for five minutes at $300 \mathrm{~g}$ and supernatants were transferred to fresh cell culture plates and frozen at $-20{ }^{\circ} \mathrm{C}$ until further analysed.

\section{Stimulation of whole blood}

Blood was withdrawn under authorised supervision from six healthy donors who had given their informed consent. $100 \mu \mathrm{l}$ of a PBS suspension containing corn starch, the four different Holi colours or LPS respectively was mixed with $1 \mathrm{ml}$ of a $0.9 \% \mathrm{NaCl}$ solution (Fresenius Kabi Deutschland GmbH, Bad Homburg, Germany). Subsequently $100 \mu \mathrm{l}$ of lithium heparin anti-coagulated whole blood was added, samples were mixed carefully and stimulated in sterile $1.5 \mathrm{ml}$ safe-lock tubes (Biopur, Eppendorf AG, Hamburg, Germany) overnight at $37{ }^{\circ} \mathrm{C}$ and $5 \% \mathrm{CO}_{2}$. The final concentration of corn starch and the four different Holi colours was $6.8 \times 10^{5}$ particles $/ \mathrm{ml}$ and for LPS it was $45.45 \mathrm{ng} / \mathrm{ml}$. PBS only served as negative control. Samples were then mixed carefully and centrifuged for $5 \mathrm{~min}$ at $300 \mathrm{~g}$ and supernatants were transferred to fresh Eppendorf tubes and frozen at $-20^{\circ}$ $\mathrm{C}$ until further analysed.

\section{Analysis of cytokine production by ELISA}

The concentration of the cytokines TNF- $\alpha$, IL- 6 and IL$1 \beta$ in the supernatant was determined using commercially available ELISA kits (R\&D Systems, Minneapolis, USA) following the manufacturer's instructions. PBMC samples were blocked with $300 \mu \mathrm{l} 1 \%$ BSA (Bovine Serum Albumin) (Sigma Aldrich, St. Louis, USA) in PBS and whole blood with $300 \mu \mathrm{l} 3 \% \mathrm{BSA}$ in PBS.

ELISA data are presented as mean \pm SD (standard deviation) values from six independent experiments. Statistical analysis was performed using SPSS software version 18 (SPSS Inc., Chicago, USA). The Wilcoxon matched pairs signed-ranked test was used to test for group differences. $P$-values $<0.05$ (two-tailed) were considered as significant.

\section{Analysis of endotoxin content of samples by Limulus Amebocyte Lysate test (LAL test)}

The endotoxin content of an unstimulated control, Holi colours 1-4, corn starch and LPS was determined using a commercially available Limulus Amebocyte Lysate test kit (Pierce ${ }^{\oplus}$ LAL Chromogenic Endotoxin Quantitation Kit, Pierce Biotechnology, Rockford, USA) as described by the manufacturer. Corn starch and Holi colour samples were applied in duplicate at $1.5 \times 10^{6}$ particles $/ \mathrm{ml}$, LPS at $100 \mathrm{ng} / \mathrm{ml}$.

\section{XTT test}

$100 \mu \mathrm{l}$ HepG2 cells $\left(\mathrm{c}=2.5 \times 10^{5}\right.$ cells $/ \mathrm{ml}$, Leibniz Institut, DSMZ, Braunschweig, Germany) were disseminated in RPMI 1640 media (Sigma-Aldrich Chemie $\mathrm{GmbH}$, München, Germany) supplemented with $10 \%$ (v/v) FCS (Sigma-Aldrich Chemie GmbH, München, Germany) in a 96 well plate (Cellstar, Greiner Bio One International $\mathrm{GmbH}$, Leipzig, Germany) and incubated over night at $37{ }^{\circ} \mathrm{C}$ and $5 \% \mathrm{CO}_{2}$ for adherence. Then media was discarded and replaced by $100 \mu \mathrm{l}$ RPMI 1640 supplemented with $1 \%$ (v/v) FCS. Subsequently $100 \mu \mathrm{l}$ of a single Holi colour or corn starch suspension in PBS were added at a final concentration of 1.7 $\times 10^{6}, 2.5 \times 10^{6}, 5 \times 10^{6}$ and $1 \times 10^{7}$ particles $/ \mathrm{ml}$, each in quadruplicate. After $4 \mathrm{~h}$ of incubation cells were washed with PBS and supplemented with $100 \mu \mathrm{l}$ of fresh RPMI 1640 containing $1 \%(\mathrm{v} / \mathrm{v})$ FCS. Then $50 \mu \mathrm{l}$ of XTT reagent was added according to the manufacturer's instructions (Cell Proliferation Kit II (XTT), product number 11465015001, Sigma-Aldrich Chemie GmbH, München, Germany). After $3 \mathrm{~h}$ of incubation at $37{ }^{\circ} \mathrm{C}$ and $5 \% \mathrm{CO}_{2}$ samples were mixed thoroughly and measured on a microplate reader (Anthos Zenyth 200RT, Biochrom, Cambridge, UK) at $490 \mathrm{~nm}$ (reference wavelength $690 \mathrm{~nm}$ ). Vitality of cells was calculated in percent in relation to an unstimulated control sample. 


\section{Propidium iodide test}

$500 \mu \mathrm{l}$ Jurkat cells $\left(\mathrm{c}=1 \times 10^{6}\right.$ cells $/ \mathrm{ml}$, Leibniz Institut, DSMZ, Braunschweig, Germany) in RPMI 1640 media supplemented with $10 \%(\mathrm{v} / \mathrm{v})$ FCS were disseminated in a 24 well plate (Cellstar, Greiner Bio One International $\mathrm{GmbH}$, Leipzig, Germany). Then $500 \mu \mathrm{l}$ of single Holi colour or corn starch suspension in PBS were added to reach a final concentration of $1.7 \times 10^{6}, 2.5 \times 10^{6}, 5 \times 10^{6}$ and $1 \times 10^{7}$ particles $/ \mathrm{ml}$, respectively. Samples were incubated for $4 \mathrm{~h}$ and for $20 \mathrm{~h}$ at $37{ }^{\circ} \mathrm{C}$ and $5 \% \mathrm{CO}_{2}$. After washing with $1 \mathrm{ml}$ PBS cells were suspended in $1 \mathrm{ml}$ fresh media without FCS and phenol red (RPMI 1640, Sigma-Aldrich Chemie GmbH, München, Germany), incubated for $15 \mathrm{~min}$ with $8 \mu \mathrm{g} / \mathrm{ml}$ propidium iodide (Sigma-Aldrich Chemie GmbH, München, Germany) in the dark at room temperature and analysed by Flow Cytometry (FACS Calibur, BD Biosciences). Vitality of cells was calculated in percent in relation to an unstimulated control sample.

\section{Light Microscopy of corn starch and Holi colours together} with human leukocytes

Blood was withdrawn under authorised supervision from two healthy donors who had given their informed consent. Cells were treated as described for the stimulation of PBMCs and stimulation of whole blood. After the $4 \mathrm{~h}$, respectively overnight incubation, $20 \mu \mathrm{l}$ of the cell-corn starch or cell-Holi colour mixture was pipetted onto an object slide, covered with a cover slip and immediately analysed under a light microscope (Axio Vert A1 with Axiovision Rel.4.8.2 software, Zeiss, Jena, Germany). Some of the whole blood samples were also stained with Syto 9 (Life Technologies, USA,) for $10 \mathrm{~min}$ as described by the manufacturer and analysed under the microscope in the green fluorescence channel.

\section{Phagoburst Assay}

Blood was withdrawn under authorised supervision from four healthy donors who had given their informed consent. Phagoburst ${ }^{\mathrm{Tm}}$ reagent Kit (Glycotope Biotechnology, Germany) was used to measure the oxidative burst activity of monocytes and granulocytes in human whole blood as described by the manufacturer except for the incubation time at $37{ }^{\circ} \mathrm{C}$ which was reduced to overall $12 \mathrm{~min}$ instead of $20 \mathrm{~min}$ due to a reduced cell viability observed at the longer incubation time. Additionally to the reagents in the kit, corn starch and Holi colour 1 were incubated with the heparinised human whole blood. The concentrations of corn starch and Holi colour 1 corresponded to the E.coli (Escherichia coli) concentration of $2 \times$ $10^{9}$ particles $/ \mathrm{ml}$. Samples remaining on ice served as negative control.

\section{Analysis of mould content}

$100 \mu \mathrm{l}$ of each Holi colour and corn starch suspension $\left(\mathrm{c}=1.5 \times 10^{6}\right.$ particles $\left./ \mathrm{ml}\right)$ was inoculated under sterile conditions on malt extract agar (MEA, OXOID GmbH, Wesel, Germany) and Dichloran 18 \% Glycerol agar (DG18, heipha Dr. Müller GmbH, Eppelheim, Germany). The agar plates were incubated at $25{ }^{\circ} \mathrm{C}$ and $36{ }^{\circ} \mathrm{C}$ for 10 days, respectively. The micro-morphology of selected colonies was analysed by optical microscopy (Axioskop $40 \mathrm{FL}$, Carl Zeiss MicroImaging GmbH, Göttingen, Germany) at $200 \times$ and $1000 \times$ magnification and subsequently photographed with a digital camera (Canon PowerShot Gs, Canon Deutschland, Krefeld, Germany).

\section{Results}

The tested Holi colours consist of more than $40 \%$ PM10 particles

We analysed commercially available particles of known size, corn starch - often used as Holi colour carrier substance - and four different Holi powders regarding particle size and number by use of a CASY ${ }^{\circ}$ Cell Counter (Fig. 1). BD Cytometer Setup and Tracking beads of 2 and $3 \mu \mathrm{m}$ diameters mixed with blank calibration particles of 6.0 $6.4 \mu \mathrm{m}$ diameter show precise peaks at the respective sizes (Fig. 2a), thus confirming $\mathrm{CASY}^{\circ}$ Technology as an accurate method regarding particle size characterisation. To identify the inhalable fraction of the analysed particles the percentage of counts $<10 \mu \mathrm{m}$ in diameter was determined. Because of background artefacts the range from 0 to $0.7 \mu \mathrm{m}$ was excluded. This resulted in a gate set between 0.7 and $10 \mu \mathrm{m}\left(\mathrm{P}_{0.7-10 \mu \mathrm{m}}\right.$ in Fig. 1$)$. The content of particles between 0.7 and $10 \mu \mathrm{m}$ in diameter varied between the analysed powders: corn starch consisted to $51 \%$ of particles $>0.7 \mu \mathrm{m}$ and $<10 \mu \mathrm{m}$ (Fig. $1 \mathrm{~b}$ ) while the content of particles between 0.7 and $10 \mu \mathrm{m}$ in the Holi colours ranged from 43 to $80 \%$ (Fig. 1c-f). Thus all four Holi powders consisted of more than $40 \%$ potentially inhalable particles that might reach the lower respiratory tract.

\section{Holi colours can induce the production of TNF- $a$, IL- 6 and IL-1 $\beta$}

To assess the pro-inflammatory capacity of the different Holi colours, we tested their potential to induce the production of the pro-inflammatory cytokines TNF- $\alpha$, IL-6 and IL-1 $\beta$. We used two different cell culture systems and two different incubation times: human PBMCs were incubated for $4 \mathrm{~h}$ and human whole blood was incubated overnight with corn starch and four different Holi colours. The resulting cytokine production was analysed by ELISA. Cells treated with PBS only served as unstimulated control and cells treated with LPS served as positive control.

In both cell culture systems, cells incubated with corn starch or Holi colours showed a higher production 


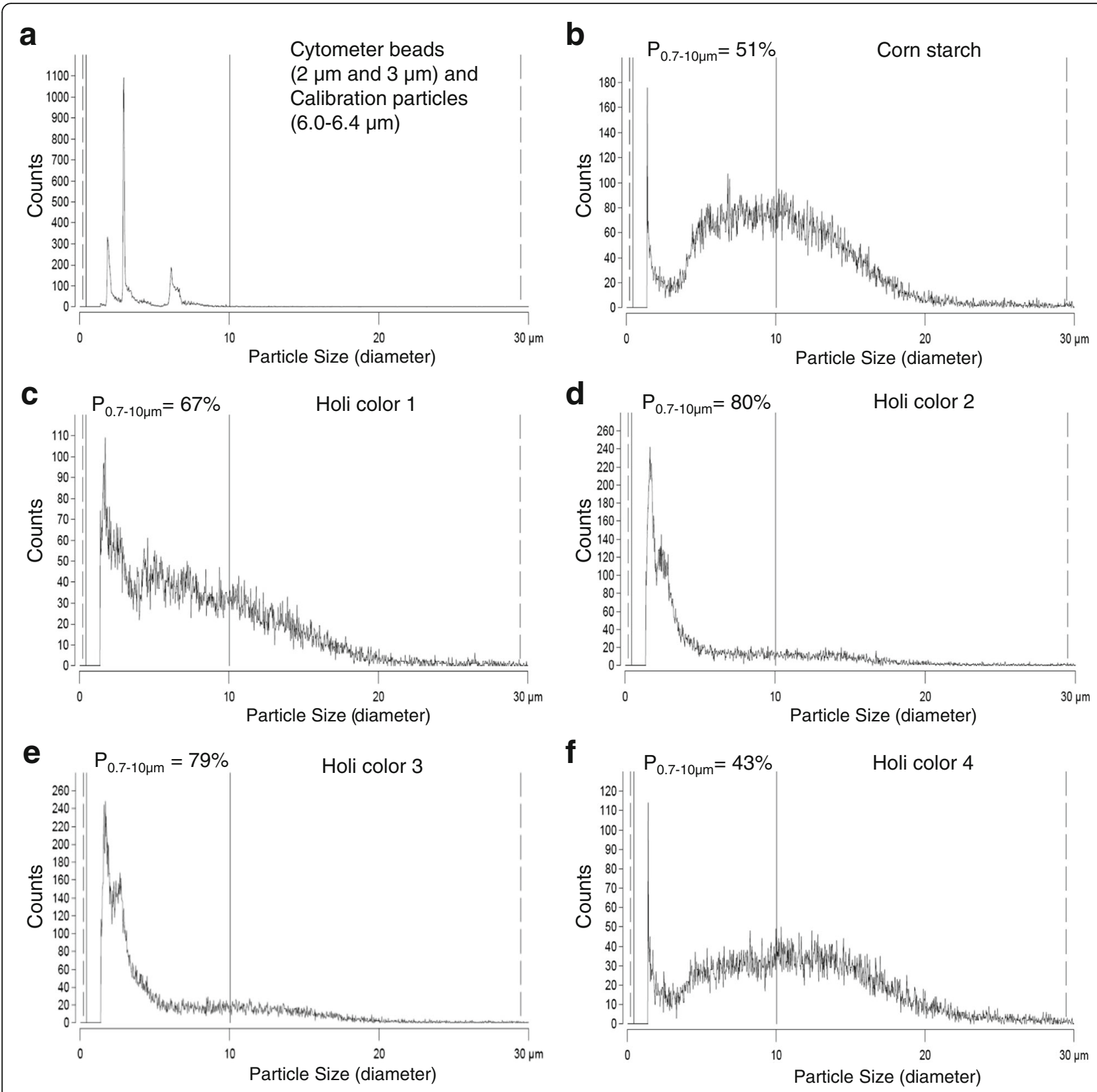

Fig. 1 Particle size distribution of beads, corn starch and Holi colours. Illustrated is the particle size distribution of commercially available beads

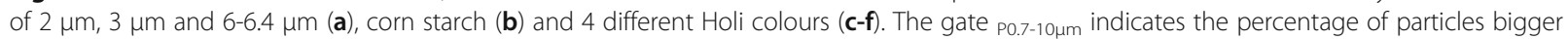
than the detection limit of $0.7 \mu \mathrm{m}$ but smaller than $10 \mu \mathrm{m}$ in diameter

of TNF- $\alpha$, IL- 6 and IL- $1 \beta$ than unstimulated cells (Fig. 2). This increase was significant $(p<0.05)$ for all analysed cytokines and all Holi samples except for Holi colour 2. Holi colours 1,3 and 4 induced a significantly higher cytokine production than corn starch $(p<0.05$ for TNF- $\alpha$, IL-6 and IL-1 $\beta)$. Corn starch also slightly increased the production of TNF$\alpha$, IL- 6 and IL-1 $\beta$ when compared to the cells treated with PBS only (Fig. 2). This increase was significant $(p<0.05)$ for TNF- $\alpha$, IL-6 and IL-1 $\beta$ in
PBMCs and for IL- 6 and IL-1 $\beta$ in the whole blood experiments.

\section{Corn starch and Holi colours 3 and 4 contain endotoxin}

As endotoxin is a potent inducer of pro-inflammatory cytokines [8], an endotoxin quantification test was performed to determine the endotoxin content of corn starch and the different Holi colours. Hereby, the same particle and LPS concentration was used as for the stimulation of PBMCs. In the unstimulated control and 

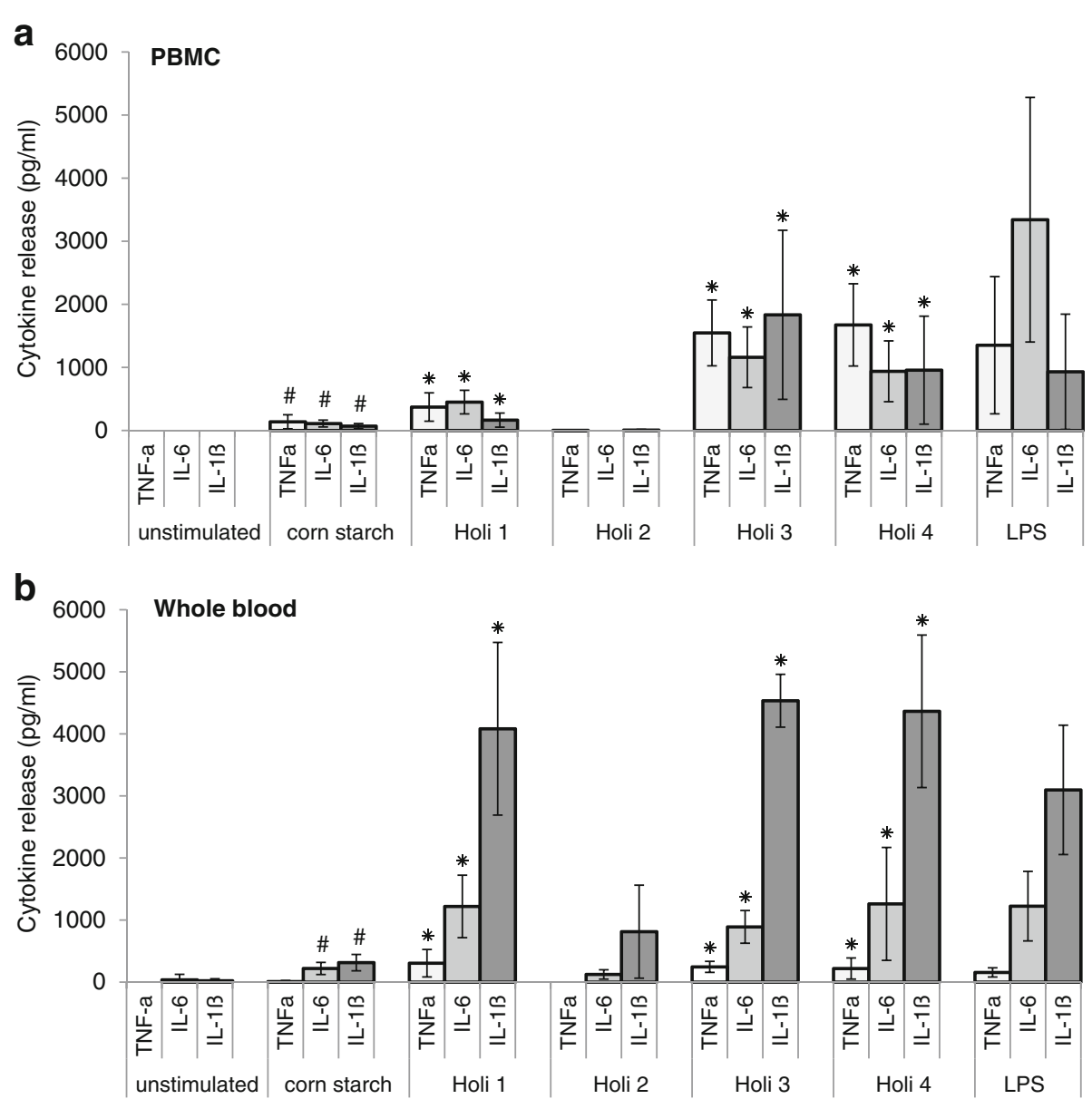

Fig. 2 Induction of pro-inflammatory cytokines by corn starch and Holi colours. Shown is the production of TNF-a, IL-6 and IL-1 $\beta$ induced by corn starch and Holi colours 1-4 in (a) PBMCs and (b) whole blood. PBS served as negative and LPS as positive control. Each bar represents the mean value of six independent experiments representing 6 different probands. The standard deviation is depicted by the error bars. \# significant $(p<0.05)$ when compared to unstimulated cells. * significant $(p<0.05)$ when compared to unstimulated cells and cells treated with corn starch

in Holi colours 1 and 2 no endotoxin was detectable, while corn starch exhibited an endotoxin level of 0.11 $\mathrm{EU} / \mathrm{ml}$ (Endotoxin Units/ml), Holi colour 3 of $0.23 \mathrm{EU} /$ $\mathrm{ml}$, Holi colour 4 of $1.99 \mathrm{EU} / \mathrm{ml}$ and the positive control LPS of $9 \mathrm{EU} / \mathrm{ml}$ (Fig. 3).

\section{Holi colour 2 and 3 show cytotoxicity with increasing particle concentration}

To determine possible cytotoxic effects of Holi colours and corn starch we performed two different cytotoxicity tests: the XTT test and the Propidium iodide test. The XTT test revealed that neither corn starch nor Holi colours 1, 3 or 4 exhibited cytotoxicity towards HepG2 cells in the concentration range tested. Holi colour 2 showed no cytotoxicity in the lowest concentration $\left(1.7 \times 10^{6}\right.$ particles $/ \mathrm{ml}$ ) but cytotoxicity increased with raising particle concentration (data not shown). In the Propidium iodide test corn starch and Holi colours 1, 2 and 4 did not show any cytotoxic effects. Holi colour 3 displayed

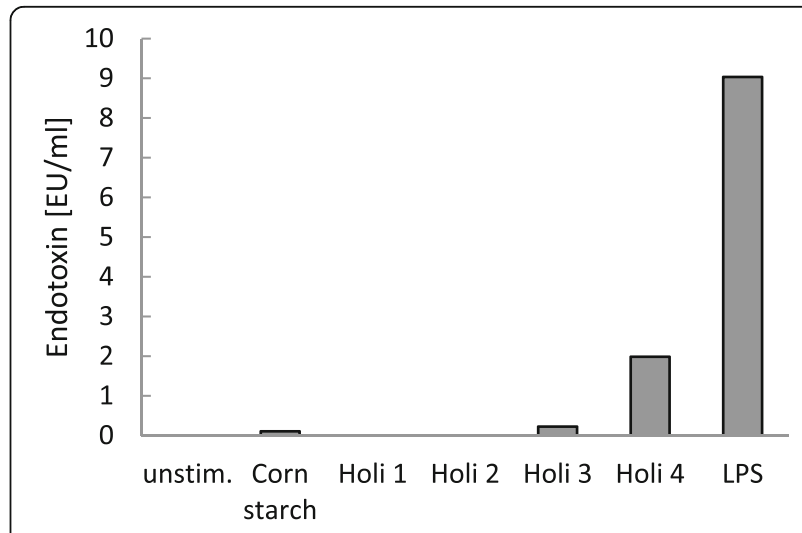

Fig. 3 Endotoxin content of corn starch and Holi colours 1-4. The endotoxin content of corn starch and Holi colours 1-4 was determined by $L A L$ test. The resulting endotoxin amount was measured in Endotoxin Units per $\mathrm{ml}(\mathrm{EU} / \mathrm{ml})$. Samples were applied in the same concentration as used for stimulation of PBMCs (corn starch and Holi colours 1-4: $c=1.5 \times 10^{6}$ particles $/ \mathrm{ml}$, LPS: $100 \mathrm{ng} / \mathrm{ml}$ ) 
increasing cytotoxicity with increasing particle concentration (data not shown). But due to interferences with the fluorescence of the Holi colours and the fluorescence to be measured by flow cytometry, the evaluation of the Propidium iodide test was very difficult and the data should be considered preliminary.

\section{Holi colour particles are associated with human leukocytes in the microscopic image}

Human PBMCs and human whole blood were incubated for $4 \mathrm{~h}$ and overnight with corn starch and four different Holi colours to determine the fate of the particles when administered to cells and to test for possible cell-particle-interactions.

Light Microscopy of human PBMCs together with Holi colours and corn starch demonstrated the irregular shape of the bigger particles (radius of about 3 to $10 \mu \mathrm{m})$ and showed an even distribution of cells and particles (Fig. 4a-e). Due to the autofluorescence of Holi colours 2, 3 and 4, Holi particles could be visualised by Fluorescence Microscopy. When cells were stained with the nucleic acid dye Syto 9, this revealed a close particle- cell-association of the smaller Holi particles with human leukocytes as shown in Fig. 4f for Holi colour 3.

\section{Holi colour 1 and corn starch can induce an oxidative burst in human granulocytes and monocytes}

We incubated human whole blood $(n=4)$ with corn starch and the different Holi colours and determined the resulting leukocyte oxidative burst by flow cytometric analysis. Due to interference of the autofluorescence of Holi colours 2, 3 and 4 with the fluorescence measured as a result of the oxidative burst, only corn starch and Holi colour 1 could be tested. Preliminary data revealed that 29.5-39.3 \% of human granulocytes and 11.4$25.7 \%$ of human monocytes produced reactive oxidants after incubation with corn starch. Holi colour 1 induced an oxidative burst in 16-24.1\% of human granulocytes and $2.7-4.3 \%$ of human monocytes (Fig. 5).

\section{Holi colour 1 contains mould fungi}

Agar plates inoculated with Holi colour 1 exhibited fungal growth of several macromorphologically different colonies (Fig. 6a). Fungal growth was not observed on
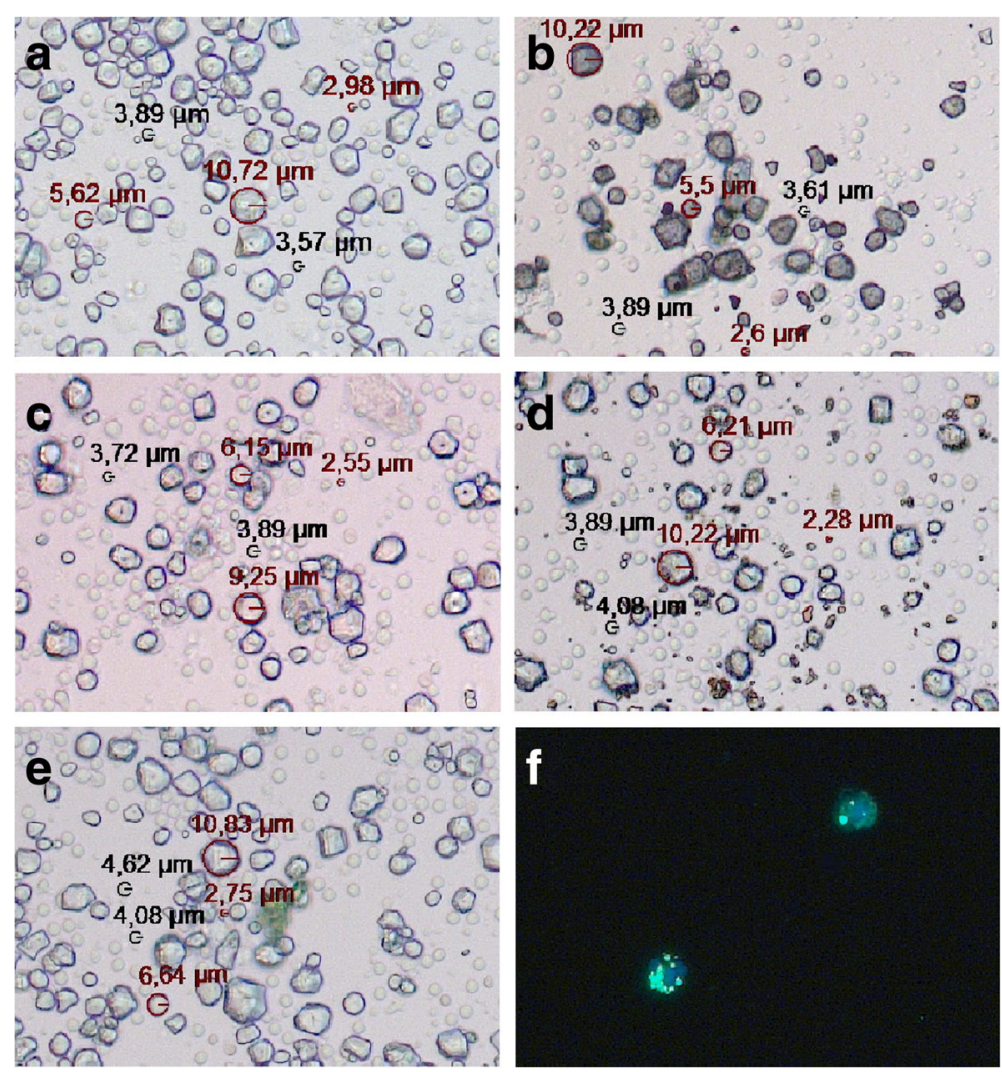

Fig. 4 Light Microscopic images of human PBMCs together with Holi colours or corn starch. a-e shows 200 fold magnifications of native preparations of human PBMCs incubated for $4 \mathrm{~h}$ together with corn starch (a), Holi colour 1 (b), Holi colour 2 (c), Holi colour 3 (d) and Holi colour 4 (e). Cell sizes are indicated in black and particle sizes in red and the respective radiuses are stated. (Note that very small particles could not be indexed.) $\mathbf{f}$ displays a 400 fold magnification of cells incubated overnight with Holi colour 3, then stained with the nucleic acid dye Syto 9 and analysed in the green fluorescence channel 


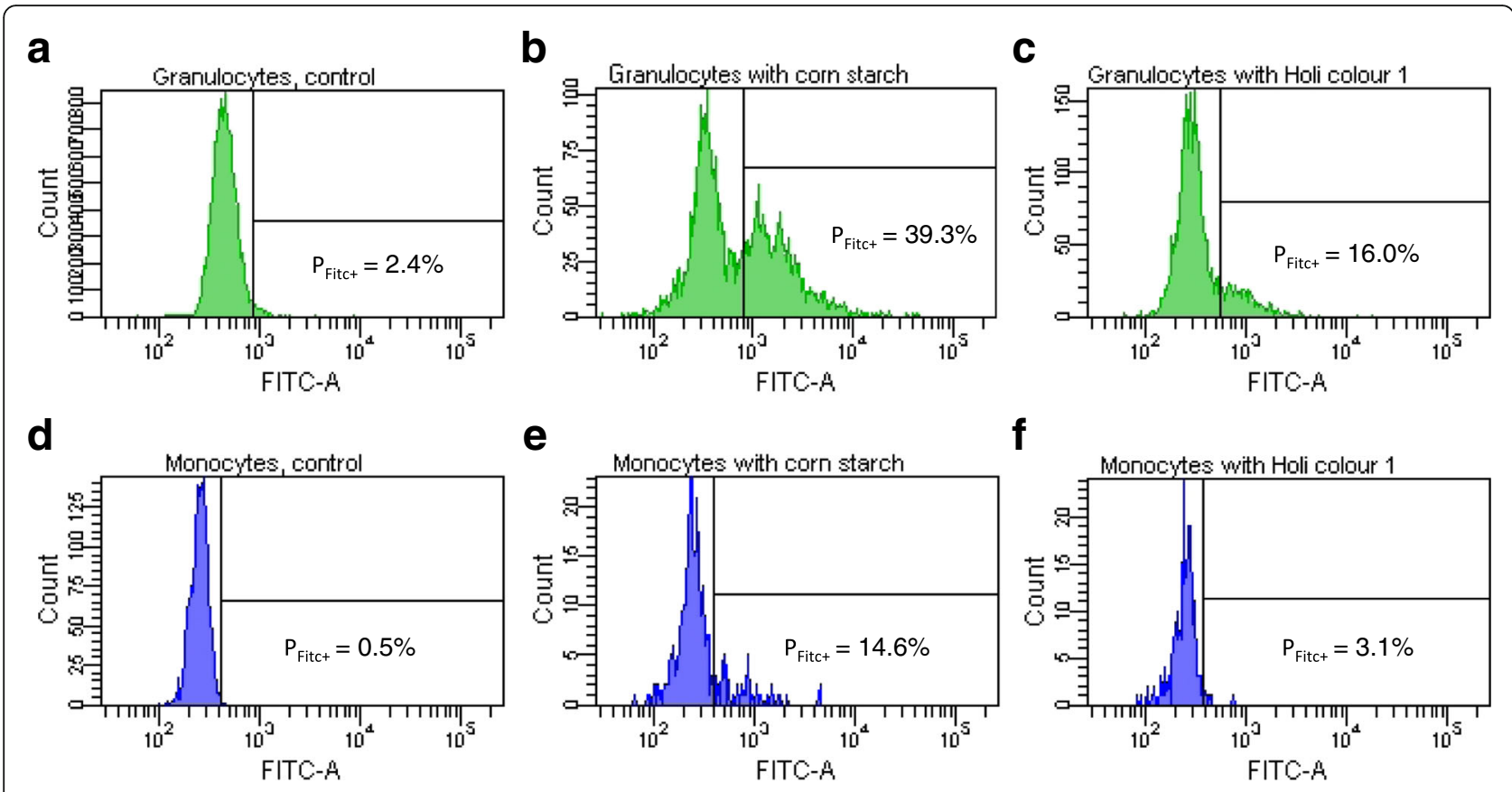

Fig. 5 Induction of leukocyte oxidative burst by corn starch and Holi colour1. Exemplified is the illustration of the percentage of granulocytes (a-c) and monocytes ( $\mathbf{d}-\mathbf{f}$ ) which produce reactive oxidants in one proband after $\mathbf{a}$ and $\mathbf{d}$ : incubation with corn starch at $0{ }^{\circ} \mathrm{C}$ (negative control); b and e: incubation with corn starch at $37^{\circ} \mathrm{C}$; $\mathbf{c}$ and $\mathbf{f}$ : incubation with Holi colour 1 at $37^{\circ} \mathrm{C}$. The gate $\mathrm{P}_{\mathrm{FITC}+}$ displays the particles considered FITC positive and respective percentages are given
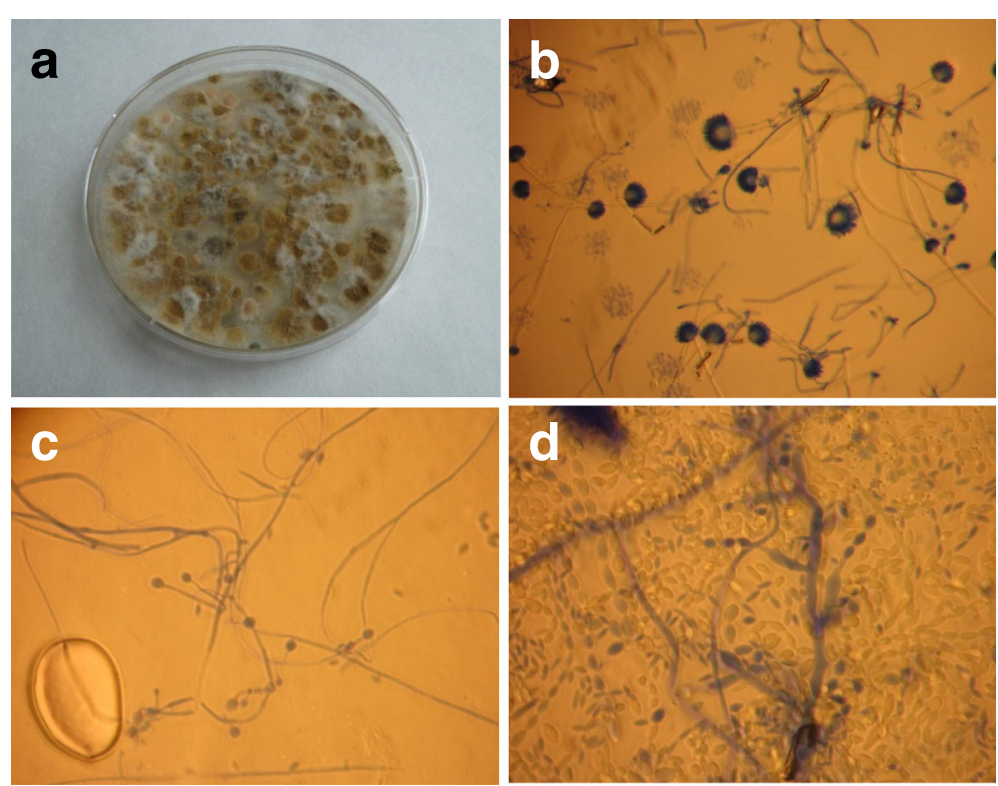

Fig. 6 Holi colour 1 contains mould. a exhibits a photograph of a DG18 agar plate after inoculation with Holi colour 1 and incubation for 10 days at $25^{\circ} \mathrm{C}$. $\mathbf{b}$ - $\mathbf{d}$ displays microscopic images of different isolates of mould fungi (b Aspergillus sp., $\mathbf{c}$ unidentified Zygomycete species, $\mathbf{d}$ unidentified Paecilomyces/Bossychlamus species) found in Holi colour 1 (Magnification: 200x) 
plates inoculated with Holi colours 2-4 and corn starch (data not shown).

By micromorphological analysis different isolates of Aspergillus spp., unidentified Zygomycete species and unidentified Paecilomyces/Bossychlamus species were detected (Fig. 6b-d).

\section{Discussion}

Holi colours can potentially be harmful to human health: they contain a considerable amount of particles with an aerodynamic diameter smaller than $10 \mu \mathrm{m}$ and at least in vitro they show a close association with human leukocytes, a pro-inflammatory potential, they can have cytotoxic effects in higher concentration and can induce an oxidative burst in human granulocytes and monocytes.

Extensive use of Holi powder at Holi festivals will result in a considerable increase in PM10 concentrations in ambient air. Adverse health effects due to long-term exposure to high PM10 concentrations are widely known: increasing concentrations of particulate matter are related to a higher cardiovascular and respiratory morbidity and mortality [9-13]. Also, there is evidence for short-term effects of air pollutants: increased PM10 concentrations were also associated with an increase in daily mortality $[14,15]$. In addition, a positive association of dust storms with mild asthma manifestations in children, as indicated by medication purchases, could be shown recently [16].

In this study the particle size of the examined Holi colours differed (Fig. 1). While Holi colours 2 and 3 consisted of about $80 \%$ of particles smaller than $10 \mu \mathrm{m}$ in diameter - with the majority of particles being even smaller than $5 \mu \mathrm{m}$ (Fig. 1d-e) -, the particle size of Holi colours 1 (Fig. 1c) and 4 (Fig. 1f) ranged between 0.7 and $20 \mu \mathrm{m}$ with a PM10 content of 67 and $43 \%$, respectively.

The size resolution in the $\mathrm{CASY}^{\circ}$ analysis confirmed approximately the average particle size of corn starch (Fig. 1b) stated in the literature: $15 \mu \mathrm{m}$ in diameter [17]. But except for Holi colour 4 the other colours contained a greater number of smaller particles. Thus, the corn starch used for Holi colour production might be somehow modified during the colour production process or mixed with other substances. For the Holi colours 1, 3 and 4 it is also possible that they comprise another carrier substance, e.g. rice flour or other anticaking agents.

It is difficult to compare the specific exposure at/or in the vicinity of Holi festivals with the "normal" ambient PM10 exposure i.e. caused by road traffic or combustion processes. The composition of the particulate matter seems to have a great influence on the biological effects as i.e. assessed by cytokine induction [18]. Also epidemiological data show that not only the particle size but furthermore the chemical composition accounts for harmful health effects $[19,20]$.

In this study, the four different Holi colours induced diverging amounts of pro-inflammatory cytokines as shown in the cell culture experiments (Fig. 2). Differences in the proportion of particle size alone cannot account for the different levels of pro-inflammatory potential: although Holi colours 2 and 3 had nearly the same amount of particles $>0.7 \mu \mathrm{m}$ and $<10 \mu \mathrm{m}$ (about $80 \%$ ), they induced significantly diverging amounts of TNF- $\alpha$, IL- 6 and IL- $1 \beta$.

In general as compared to PBMCs, which were stimulated for $4 \mathrm{~h}$, (Fig. 2a) we found a decrease in TNF- $\alpha$ production and an increase in IL-1 $\beta$ production in the whole blood experiments (Fig. 2b), where cells were incubated with the respective substances overnight. This corresponds well with the kinetics of release of TNF- $\alpha$ and IL-1 $\beta$ in whole blood and PBMCs: TNF- $\alpha$ reaches maximal levels within $6 \mathrm{~h}$ of stimulation, whereas IL-1 $\beta$ reaches maximal levels between 12 and $16 \mathrm{~h}[21,22]$.

The release of the pro-inflammatory cytokines TNF- $\alpha$, IL- 6 and IL-1 $\beta$ by human cells stimulated in vitro with particulate matter PM10 or nanoparticles has been shown in various studies [18, 23-27]. The fact that exposure to swine dust in vivo also leads to an increase of TNF- $\alpha$, IL- 6 and IL-1 $\beta$ in peripheral blood of healthy volunteers [28] suggests, that these cytokines might also be able to mediate this kind of inflammatory response in vivo.

Endotoxin is a potent inducer of various proinflammatory cytokines [8]. To elucidate the role of endotoxin in the cytokine induction of the Holi colours, we measured the amount of endotoxin in the different Holi samples by means of the LAL test. We did not detect any endotoxin in Holi colours 1 and 2, but discovered endotoxin in corn starch as well as in Holi colours 3 and 4, albeit these amounts of endotoxin are much below the endotoxin level measured in LPS (Fig. 3). But since already very low amounts of endotoxin in the picogramme range (which represent Endotoxin units of 1 $\mathrm{EU} / \mathrm{ml}$ or even below according to the manufacturer's product guide of the LAL test used here) can be responsible for considerable cytokine secretions the observed cytokine induction of Holi colours 3 and 4 might be caused by endotoxin. (We performed dose response tests for endotoxin levels and cytokines of interest. The results will be subject of a separate publication.) Nevertheless as Holi colour 1 contains no endotoxin and Holi colours 3 and 4 contained lesser endotoxin than LPS but induced a stronger cytokine release, we argue that also other factors than endotoxin might drive the cytokine answer.

Hansen et al. have shown that the potency of endotoxin from different Gram-negative bacteria in the LAL- 
assay is not closely correlated with the potency of the endotoxin to induce IL-8 (Interleukine-8) secretion from pulmonary epithelial cells [29]. This observation might be true for other pro-inflammatory cytokines as well. Hence the results of the LAL-test do not necessarily have to correlate with the cell culture data. This would also explain why corn starch, which contained endotoxin, only induces a very low cytokine release.

The XTT test and Propidium iodide test showed possible cytotoxic effects of Holi colours 2 and 3 with increasing Holi colour concentration, while corn starch and Holi colours 1 and 4 did not display any cytotoxicity thus underlying the heterogeneity of Holi colours. Since the observed cytotoxicity occurs only at higher concentrations or is rather less pronounced in the lowest concentration tested, respectively, their relevance to health regarding a real Holi festival situation would need further investigation.

Although fluorescence microscopy (Fig. 4f) showed a close particle-cell-association the nature of this association remains unclear: are the particles bound to the cell surface and if so through what kind of receptor or are the particles phagocytosed by the cell? Due to the impossibility of quenching the autofluorescent signal of the Holi colours in the flow cytometric analysis an exact discrimination of particles bound to the cell surface and particles phagocytosed by the cell was not feasible and we were not able to show an internalisation of Holi particles directly (data not shown). But as corn starch and to a lesser extent also Holi colour 1 induced an oxidative burst in human granulocytes and monocytes (Fig. 5), one can speculate that these cells might engulf the particles. However, the limitation remains, that the Phagoburst assay is an in vitro setup that is very different from the situation in vivo regarding i.e. time of exposure and particle concentration. Still, phagocytosis and processing of particulate matter by the macrophages in the lung is an established phenomenon which leads to diverse immunological responses and cytokine release [30].

Aspergillus spp. as well as other filamentous fungi could be detected in Holi colour 1 (Fig. 6). Moulds in general pose a risk to human health, can be involved in disorders of the respiratory tract and may contribute to the manifestation of asthma and allergies [31]. As Kawakami et al. [32] and Wykoff et al. [33] reported, Aspergillus and Paecilomyces species can play a role in ocular infections with soft contact lens use as one predisposing factor. In the context of numerous ocular irritations reported by medical services on Holi festivals (Becker et al., submitted) this detection of fungi may be of clinical relevance. Deeper insights in the microbiological contamination profile of Holi colours might be of interest for future investigations.

Not much is known about the ingredients of the Holi colours (see Table 1). Even the carrier substance often remains unknown. As the composition (carrier substance, colour pigments, anticaking agents, etc.) varies from colour to colour, also the observed in vitro effects differ. Similarly, underlying mechanisms as well as the generation of possible health effects might be diverse and dependent on the specific colour. However, these various modes of action might also work in an additive or synergistic fashion as i.e. endotoxin, fungal contamination and leukocyte oxidative bursts might potentially lead to the observed induction of pro-inflammatory cytokines. Further experiments are needed to elucidate the distinct underlying mechanisms in more detail.

\section{Conclusion}

Holi festivals - with intense throwing of Holi powder in the air - are becoming popular all over the world. Although adverse health effects like skin, ocular or respiratory irritations may be the consequence, the hazard of Holi powder and possible underlying mechanisms of harmful effects have not been studied so far. We show here that the composition and the observed in vitro effects differ from colour to colour: Holi colours can contain up to $80 \%$ of PM10 particles, they can have a pro-inflammatory and a cytotoxic potential, they can induce a leukocyte oxidative burst and they might be contaminated with mold fungi. These facts may account for some of the observed adverse health effects described by participants of Holi festivals and may improve the risk assessment of Holi colours.

\section{Acknowledgements \\ Not applicable. \\ Funding \\ This study has no external funding.}

Availability of data and materials

Not applicable.

\section{Authors' contributions}

KB designed the study and carried out the data analysis together with SB. $\mathrm{CH}$ performed the statistical analysis. KS drafted the manuscript. $\mathrm{RH}$ performed various toxicological tests and KV analysed the mycological aspects. AN and WS advised on particulate matter health effects issues and revised the manuscript. All authors participated in the study conception and coordination and read and approved the final manuscript.

\section{Competing interests}

The authors declare that they have no competing interests.

\section{Consent for publication}

Not applicable.

\section{Ethics approval and consent to participate}

Ethics approval was provided by the Ethics Committee of the Ärztekammer Berlin, Germany (reference number: Eth-20/14). All participants had given their informed consent to participate in this study.

\section{Author details}

${ }^{1}$ Environmental Medicine and Health Effects Assessment, Federal Environment Agency, Corrensplatz 1, 14195 Berlin, Germany. ${ }^{2}$ Microbiological Risk Assessment, Federal Environment Agency, Corrensplatz 1, 14195 Berlin, 
Germany. ${ }^{3}$ Toxicology of drinking water, Federal Environment Agency, Heinrich-Heine-Str. 12, 08645 Bad Elster, Germany.

\section{Received: 1 June 2015 Accepted: 17 August 2016} Published online: 10 September 2016

\section{References}

1. Ghosh SK, Bandyopadhyay D, Chatterjee G, Saha D. The 'holi' dermatoses: annual spate of skin diseases following the spring festival in India. Indian J Dermatol. 2009;54(3):240-2.

2. Velpandian T, Saha K, Ravi AK, Kumari SS, Biswas NR, Ghose S. Ocular hazards of the colors used during the festival-of-colors (Holi) in India-malachite green toxicity. J Hazard Mater. 2007;139(2):204-8.

3. Chauhan D, Arora R, Das S, Shroff D, Narula R. Bilateral periorbital necrotizing fasciitis following exposure to Holi colors: a case report. Indian J Ophthalmol. 2007;55(5):373-4

4. Pachauri T, Singla V, Satsangi A, Lakhani A, Kumari KM. Characterization of major pollution events (dust, haze, and two festival events) at Agra, India. Environ Sci Pollut Res Int. 2013;20(8):5737-52.

5. Hessle CC, Andersson B, Wold AE. Gram-positive and Gram-negative bacteria elicit different patterns of pro-inflammatory cytokines in human monocytes. Cytokine. 2005;30(6):311-8.

6. Schindler S, Spreitzer I, Loschner B, Hoffmann S, Hennes K, Halder M, et al. International validation of pyrogen tests based on cryopreserved human primary blood cells. J Immunol Methods. 2006;316(1-2):42-51.

7. Liebers V, Stubel H, Duser M, Bruning T, Raulf-Heimsoth M. Standardization of whole blood assay for determination of pyrogenic activity in organic dust samples. Int J Hyg Environ Health. 2009;212(5):547-56.

8. Moller W, Heimbeck I, Hofer TP, Khadem Saba G, Neiswirth M, Frankenberger $M$, et al. Differential inflammatory response to inhaled lipopolysaccharide targeted either to the airways or the alveoli in man. PLoS One. 2012; 7(4):e33505.

9. Anderson JO, Thundiyil JG, Stolbach A. Clearing the air: a review of the effects of particulate matter air pollution on human health. J Med Toxicol. 2012:8(2):166-75.

10. Chen H, Goldberg MS, Villeneuve PJ. A systematic review of the relation between long-term exposure to ambient air pollution and chronic diseases. Rev Environ Health. 2008;23(4):243-97.

11. Adam M, Schikowski T, Carsin AE, Cai Y, Jacquemin B, Sanchez M, et al. Adult lung function and long-term air pollution exposure. ESCAPE: a multicentre cohort study and meta-analysis. Eur Respir J. 2015:45(1):38-50.

12. Adar SD, Filigrana PA, Clements N, Peel JL. Ambient coarse particulate matter and human health: a systematic review and meta-analysis. Curr Environ Health Rep. 2014;1:258-74.

13. Schwartz J. Air pollution and daily mortality: a review and meta analysis. Environ Res. 1994;64(1):36-52.

14. Faustini A, Stafoggia M, Colais P, Berti G, Bisanti L, Cadum E, et al. Air pollution and multiple acute respiratory outcomes. Eur Respir J. 2013;42(2):304-13.

15. Zeka A, Zanobetti A, Schwartz J. Short term effects of particulate matter on cause specific mortality: effects of lags and modification by city characteristics. Occup Environ Med. 2005;62(10):718-25.

16. Yitshak-Sade M, Novack V, Katra I, Gorodischer R, Tal A, Novack L. Nonanthropogenic dust exposure and asthma medication purchase in children. Eur Respir J. 2015:45:652-60.

17. Jane J, Shen L, Wang L, Maningat CC. Preparation and properties of small-particle corn starch. Cereal Chem. 1992;69:280-3.

18. Monn C, Becker S. Cytotoxicity and induction of proinflammatory cytokines from human monocytes exposed to fine (PM2.5) and coarse particles (PM10-2.5) in outdoor and indoor air. Toxicol Appl Pharmacol. 1999; 155(3):245-52.

19. Pun VC, Yu IT, Qiu H, Ho KF, Sun Z, Louie PK, et al. Short-term associations of cause-specific emergency hospitalizations and particulate matter chemical components in Hong Kong. Am J Epidemiol. 2014;179(9):1086-95.

20. Bell ML, Ebisu K, Leaderer BP, Gent JF, Lee HJ, Koutrakis P, et al. Associations of PM(2). (5) constituents and sources with hospital admissions: analysis of four counties in Connecticut and Massachusetts (USA) for persons $>/=65$ years of age. Environ Health Perspect. 2014;122(2):138-44.

21. Mathiak G, Kabir K, Grass G, Keller H, Steinringer E, Minor T, et al. Lipopolysaccharides from different bacterial sources elicit disparate cytokine responses in whole blood assays. Int J Mol Med. 2003;11(1):41-4.
22. Lonnemann G, Endres S, Van der Meer JW, Cannon JG, Koch KM, Dinarello CA. Differences in the synthesis and kinetics of release of interleukin 1 alpha, interleukin 1 beta and tumor necrosis factor from human mononuclear cells. Eur J Immunol. 1989;19(9):1531-6.

23. Brown DM, Donaldson K, Borm PJ, Schins RP, Dehnhardt M, Gilmour P, et al. Calcium and ROS-mediated activation of transcription factors and TNF-alpha cytokine gene expression in macrophages exposed to ultrafine particles. Am J Physiol Lung Cell Mol Physiol. 2004;286(2):L344-53.

24. Brown DM, Donaldson K, Stone V. Effects of PM10 in human peripheral blood monocytes and J774 macrophages. Respir Res. 2004;5:29.

25. Bengalli R, Molteni E, Longhin E, Refsnes M, Camatini M, Gualtieri M. Release of IL-1 beta triggered by Milan summer PM10: molecular pathways involved in the cytokine release. Biomed Res Int. 2013;2013:158093.

26. Yazdi AS, Guarda G, Riteau N, Drexler SK, Tardivel A, Couillin I, et al. Nanoparticles activate the NLR pyrin domain containing 3 (NIrp3) inflammasome and cause pulmonary inflammation through release of IL-1alpha and IL-1 beta. Proc Natl Acad Sci U S A. 2010;107(45):19449-54.

27. Yang EJ, Kim S, Kim JS, Choi IH. Inflammasome formation and IL-1 beta release by human blood monocytes in response to silver nanoparticles. Biomaterials. 2012;33(28):6858-67.

28. Wang Z, Manninen A, Malmberg P, Larsson K. Inhalation of swine-house dust increases the concentrations of interleukin-1 beta (IL-1 beta) and interleukin-1 receptor antagonist (IL-1 ra) in peripheral blood. Respir Med. 1998;92(8):1022-7.

29. Hansen LA, Poulsen OM, Wurtz H. Endotoxin potency in the A549 lung epithelial cell bioassay and the limulus amebocyte lysate assay. J Immunol Methods. 1999;226(1-2):49-58.

30. Miyata R, van Eeden SF. The innate and adaptive immune response induced by alveolar macrophages exposed to ambient particulate matter. Toxicol Appl Pharmacol. 2011;257(2):209-26.

31. Bush RK, Portnoy JM, Saxon A, Terr Al, Wood RA. The medical effects of mold exposure. J Allergy Clin Immunol. 2006;117(2):326-33.

32. Kawakami H, Inuzuka H, Mochizuki K, Takahashi N, Muto T, Ohkusu K, et al. Clinical manifestations, treatment and outcome of ocular infections caused by Paecilomyces species. Nippon Ganka Gakkai Zasshi. 2012;116(7):613-22.

33. Wykoff CC, Flynn Jr HW, Miller D, Scott IU, Alfonso EC. Exogenous Fungal Endophthalmitis: Microbiology and Clinical Outcomes. Ophthalmology. 2008;115(9):1501-7.e2.

\section{Submit your next manuscript to BioMed Central and we will help you at every step:}

- We accept pre-submission inquiries

- Our selector tool helps you to find the most relevant journal

- We provide round the clock customer support

- Convenient online submission

- Thorough peer review

- Inclusion in PubMed and all major indexing services

- Maximum visibility for your research

Submit your manuscript at www.biomedcentral.com/submit
Biomed Central 